\title{
Letters
}

Website: www.bmj.com

Email: letters@bmj.com

\section{Smoking should be mentioned as cause of death on death certificates}

EDITOR-Tobacco related diseases cause an estimated two million deaths a year in developed countries. ${ }^{1}$ Smoking has always been permitted as a cause of death on death certificates in Britain, but such deaths had to be reported to the coroner. Since September 1992 the coroner has not needed to be notified, provided the disease causing death was given. ${ }^{2}$ We explored the inclusion of smoking as a certified cause of death from before the change in regulations up to February 1997. Since March 1992 all deaths of people registered with general practitioners in Newcastle Family Health Services Authority have been entered on to a database. ${ }^{3}$ For each death, the data entered were the patient's name and date of birth, all causes of death listed on the death certificate, and the general practitioner's name. This database was searched for any mention of smoking, cancer, and coronary heart disease from March 1992 to February 1997. A total of 18831 death certificates were reviewed. Before the new regulations smoking was rarely recorded as a cause of death. The figure shows the results.

An increase in recording smoking as a cause of death occurred after September 1992, but this effect dissipated rapidly. Smoking was identified as a main cause of death (cause I) in 93 of 135 death certificates in which it was mentioned and as cause II in the remaining 42. Smoking was mentioned in

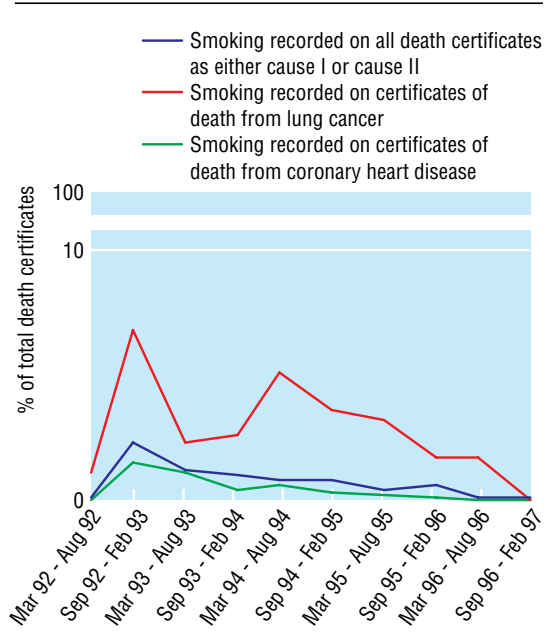

Analysis of smoking as a cause of death on death certificates

John Spencer Senior lecturer only 30 of the 1053 deaths from lung cancer (or like terms) and 20 of the 3831 deaths from coronary heart disease (or like terms).

Despite the change in regulations that made it easier to give smoking as a certified cause of death, doctors rarely use this opportunity to bring the role of smoking in mortality to wider public attention. Between $80 \%$ and $90 \%$ of cases of lung cancer ${ }^{4}$ and up to $18 \%$ of deaths from coronary heart disease $^{5}$ can be attributed to smoking. Yet smoking was rarely given on the death certificate. The clearer link between smoking and mortality that was expected to be encouraged by the change in regulation ${ }^{2}$ has not been established. The inclusion of smoking as a cause of death could be important for relatives and health agencies seeking compensation from tobacco companies for smoking related illnesses. Future studies should consider why doctors do not give smoking as a cause of death and review the justification and value of the current policy.

Louise Robinson Lecturer

Rosie Stacy Lecturer in sociology

Department of Primary Health Care, University of

Newcastle, Newcastle upon Tyne NE2 4HH

Raj Bhopal Professor

Department of Epidemiology and Public Health,

University of Newcastle

1 Peto R, Lopez AD, Boreham J, Thun M, Heath C. Mortality from tobacco in developed countries: indirect estimation from tobacco in developed countries: indirect estimat vital statistics. Lancet 1992;339:1268-78.

2 Beecham L. Smoking accepted on death certificates. BMJ 1992;305:543.

3 Berlin A, Bhopal R, Spencer J, van Zwanenberg T. Creating a death register for general practice. $\mathrm{Br} \mathrm{J} \mathrm{Gen} \mathrm{Prac}$ 1993;43:70-2.

4 Cancer Research Campaign. Lung cancer and smoking. London: Cancer Research Campaign, 1989. (Fact shee No 11.)

5 US Surgeon General. The health consequences of smoking: nicotine addiction. Washington DC: Government Printing
Office 1988. (DHSS Publication number (CDC) 88-8406.)

\section{Intermittent low dose prednisolone is safe in rheumatoid arthritis}

EDITOR-In our meta-analysis we concluded that doses of prednisolone of $\leqslant 15 \mathrm{mg}$ daily may be used intermittently in patients with rheumatoid arthritis, particularly if the disease cannot be controlled by other means. ${ }^{1}$

An accompanying editorial by Dennison and Cooper warned that doubts about the safety of this treatment remained. ${ }^{2}$ They also mentioned a number of side effects reported in a narrative review by Caldwell and Furst which we also cited in our meta-analysis (reference number 57). They complained that we had not subjected our analysis of side effects to "the full weight of the evidence based approach." ${ }^{2}$ How could we have served readers better than by collecting systematically all available results of randomised trials and matched cohort studies. Evidence based medicine relies on applying strict and explicit methodological criteria to the searching and synthesizing of the literature. This was not done in the editorial.

Dennison and Cooper argued that complications from steroids often occur at doses of $<15 \mathrm{mg}$. They justified this statement with a report from a conference sponsored by the pharmaceutical industry. ${ }^{3}$ Their editorial also cited a case-control study; we deliberately avoided such studies since they are often unreliable.

We do not dispute the fact that low dose steroids may cause bone loss. This was confirmed in a recent systematic review of prospective studies. ${ }^{4}$ However, a randomised trial comparing sulphasalazine with a combination of sulphasalazine, methotrexate, and prednisolone found that the combination regimen had a protective effect on radiological progression; this persisted when the initial dose of $60 \mathrm{mg}$ prednisolone daily was tapered to $7.5 \mathrm{mg}$ daily. ${ }^{5}$ There are other randomised trials that have shown a protective effect of low dose prednisolone.

\section{Advice to authors}

We prefer to receive all responses electromically, sent either directly to our website or to the editorial office as email or on a disk. Processing your letter will be delayed unless it arrives in an electronic form.

We are now posting all direct submissions to our website within 72 hours of receipt and our intention is to post all other electronic submissions there as well. All responses will be eligible for publication in the paper journal.

Responses should be under 400 words and relate to articles published in the preceding month. They should include $\leqslant 5$ references, in the Vancouver style, including one to the BMJ article to which they relate. We welcome illustrations.

Please supply each author's current appointment and full address, and a phone or fax number or email address for the corresponding author. We ask authors to declare any conflicts of interest.

Letters will be edited and may be shortened.

www.bmj.com

letters@bmj.com 
In contrast, it has never been shown convincingly that slow acting drugs, such as methotrexate and sulphasalazine, have an effect on radiological progression. We believe that if patients (especially those patients with early disease in whom the risk of damage is greatest) are presented with the most reliable, timely evidence they will be willing to run the small risk of getting a fracture in return for the protective effect on joint destruction. After all, fractures usually heal and bone loss may be reversible ${ }^{4}$; joint destruction is irreversible.

Low dose prednisolone does have side effects, but so do non-steroidal antiinflammatory and slow acting drugs, and the symptomatic effect is so large and the disease modifying effect so unique, that prednisolone should be used, at least intermittently. Additionally, trials have shown that it is possible to wean patients off treatment, ${ }^{15}$ which was another concern addressed by the editorial.

Peter C Gøtzsche Director

Helle Krogh Johansen Senior researcher

The Nordic Cochrane Centre, Rigshospitalet, Department 7112, Tagensvej 18 B, DK-2200

Copenhagen N, Denmark

p.c.gotzsche@cochrane.dk

1 Gøtzsche PC, Johansen HK. Meta-analysis of short term low dose prednisolone versus placebo and non-steroidal, anti-inflammatory drugs in rheumatoid arthritis. $B M$ J 1998;316:811-8. (14 March.)

2 Dennison EM, Cooper C. Corticosteroids in rheumatoid arthritis. BMJ 1998;316:789-90. (14 March.)

3 Eastel R on behalf of the UK consensus group meeting on osteoporosis. J Intern Med 1995;237:439-47.

4 Verhoeven AC, Boers M. Limited bone loss due to corticosteroids: a systematic review of prospective studies in rheumatoid arthritis and other diseases. J Rheumatol 1997;24:1495-503.

5 Boers M, Verhoeven AC, Markussen HM, Laar AFJ van de Westhovens R, Denderen JC van, et al. Randomised comparison of combined step-down prednisolone, methcomparison of combined step-down prednisolone, methearly rheumatoid arthritis. Lancet 1997:350:309-18.

\section{Octreotide for cirrhosis after variceal bleeding}

\section{Authors' claims for octreotide were not justified}

EDITOR-The conclusion drawn by Jenkins et al is that octreotide improves liver function, lowers portal pressure, and protects against variceal rebleeding. ${ }^{1}$ The paper, however, does not justify this conclusion.

Firstly, the number of patients is too small. The authors state that as long term octreotide had not been used previously in patients with cirrhosis there were no data from which to perform a power calculation. This is incorrect. Primignani et al showed no difference when subcutaneous octreotide or placebo was added for 29 days to sclerotherapy in the prevention of variceal rebleeding in 58 patients. ${ }^{2}$ In addition, there is a wealth of data that suggest that sclerotherapy reduces the incidence of variceal rebleeding to $50 \%$ at one year. The authors could have expected, at best, an additional reduction of $20 \%$ with octreotide. Using a $\beta$ of $20 \%$ and an $\alpha$ of $5 \%$, a trial of 193 patients with 77 events would be required, assuming no withdrawals and a two tailed analysis. ${ }^{3}$ Jenkins et al's trial is open to a type 2 error.

Secondly, in a trial predominantly of patients with cirrhosis of an alcoholic aetiology (23/32), no information is given on the number of patients who became abstinent Patients who are motivated to inject themselves twice a day with octreotide are also likely to be the type of patients who stop drinking. Abstinence is the single most predictive factor for a long term fall in wedge hepatic venous pressure (a marker of portal pressure) and protection against further variceal bleeding. ${ }^{4}$

On the basis of these points alone, the paper by Jenkins et al does not provide any evidence for a change in clinical practice.

D Patch Senior registrar

AK Burroughs Consultant physician

Department of Liver Transplantation and

Hepatobiliary Medicine, Royal Free Hospital,

London NW3 2OG

1 Jenkins SA, Baxter JN, Critchley M, Kingsnorth AN, Maki CA, Ellenbogen S, et al. Randomised trial of octreotide for ong term management of cirrhosis after variceal haemorrhage. BMJ 1997;315:1338-41. (22 November.)

2 Primignani M, Andreoni B, Carpinelli L, Capria A, Rocchi G, Lorenzini I, et al. Sclerotherapy plus octreotide versus , Lor sclerotherapy alone in the prevention of early rebleeding rom esophageal varices: a randomized, double-blind, placebo

3 Freedman LS. Tables of the number of patients required in clinical trials using the log rank test. Stat Med 1982;1:121-9. 4 Vorobioff J, Groszmann RJ, Picabea E, Gamen M, Villavicenzio R, Bordato J, et al. Prognostic value of hepatic venous pressure measurement in alcoholic cirrhosis: a 10 year prospective study. Gastroenterology 1996;111:701-9.

5 Coleman J, Cromie S, Jones P, Dudley E, Dudley F. Clinica relevance of sequential portal pressure measurements in alcoholic cirrhosis. Hepatology 1997;26:316A.

\section{Author's reply}

EDITOR-We began our trial before data were published that would have usefully informed a power calculation. We opted for a single centre study that would allow detailed investigation and follow up of each patient, at the expense of patient numbers. We have not made a type 2 error because we rejected the null hypothesis. In so doing we may have made a type 1 error, but nine of the 11 variables studied (including rebleeding, survival, wedged hepatic vein pressure Child's grade, and various tests of liver function) showed significant or highly significant improvements in the patients treated with octreotide. The principal exception was alkaline phosphatase, presumably because of the well recognised cholestatic effects of octreotide. ${ }^{1}$ We do not consider the trial of Primignani et al to be a study of the long term effects of octreotide as the drug was given for only four weeks. ${ }^{2}$ Neither was a detailed profile of investigations undertaken before or at the end of treatment. Although we accept appropriate statistical caution, the small size of our study does not invalidate our conclusion that long term octreotide improves liver function, lowers portal pressure, and protects against variceal rebleeding in cirrhotic portal hypertension.

The effect of abstinence from alcohol in patients with alcoholic cirrhosis is important, but Vorobioff et al studied patients with alco- holic cirrhosis who had not previously bled; their findings would have been more robust if a structured interview or biochemical assessment, or both, had been used to determine ongoing alcohol misuse or abstinence. ${ }^{3}$ Indeed, McCormick et al previously failed to show any effect of abstinence from alcohol on rebleeding or survival in patients with alcoholic cirrhosis after variceal haemorrhage. ${ }^{4}$ Our patients needed to be motivated to inject octreotide, but all of these patients were followed up intensively throughout the study. Thus all surviving patients required motivation to complete the study. If there was a genuine difference in outcome between our two groups (our results indicate that there was) then abstinence from alcohol may have contributed to this in some patients through beneficial effects on liver function and wedged hepatic vein pressure. This is unlikely, however, to account for the profound difference in outcome observed, particularly as some of our patients had cirrhosis unrelated to alcohol.

Our trial and subsequent experience with long term octreotide in similar patients convince us that octreotide may be a valuable adjuvant to endoscopic treatment for acute variceal haemorrhage in cirrhotic portal hypertension. Long acting forms of the drug may be particularly helpful. ${ }^{3}$ We are planning a large scale, multinational pragmatic study comparing the long term administration of a long acting analogue of somatostatin with $\beta$ blockade and welcome contact from any one interested.

Robert Sutton Senior lecturer in surger Clinical and Cancer Trial Unit, Department of Surgery, Royal Liverpool University Hospital, Liverpool L7 8XP

1 Gillis JC, Noble S, Goa KL. Octreotide long-acting release (LAR). A review of its pharmacological properties and therapeutic use in the management of acromegaly. Drugs 1997;53:681-99.

2 Primignani M, Andreoni B, Carpinelli L, Capria A, Rocchi G, Lorenzini I, et al. Sclerotherapy plus octreotide versus sclerotherapy alone in the prevention of early rebleeding sclerotherapy alone in the prevention of early rebleeding from esophageal varices: a randomized, double-blind, 1322-7.

3 Vorobioff J, Groszmann RJ, Picabea E, Gamen M, VillaviceVorobioff J, Groszmann RJ, Picabea E, Gamen M, Villavice-
ncio R, Bordato J, et al. Prognostic value of hepatic venous pressure gradient measurements in alcoholic cirrhosis: a 10 year prospective study. Gastroenterology 1996;111:701-9. 4 McCormick PA, Morgan MY, Phillips A, Yin TP, Mclntyre $\mathrm{N}$, Burroughs AK. The effects of alcohol use on rebleeding and mortality in patients with alcoholic cirrhosis following variceal haemorrhage.J Hepatol 1992;14:99-103.

\section{Are the media manipulating the GMC?}

EDITOR-Smith's review of media coverage of the General Medical Council draws attention to the fact that regardless of the outcome of the case in Bristol (in which two cardiothoracic surgeons and a manager are accused of operating on children despite high mortality) the GMC will lose. ${ }^{1}$ It is important that the GMC acts appropriately in this case; the GMC is on trial as much as, if not more than, the doctors from Bristol. Because this trial has been driven by the media from the outset there is a widespread perception that the GMC is determined to 
show that the profession is capable of self regulation, even at the price of scapegoating the few to maintain self regulation.

In the Bristol case the GMC's professional conduct committee has one responsibility: to reach a decision based only on the evidence put before it. Those who have followed the events in the national press will believe that the doctors are guilty, not only because the press had come to that conclusion before the trial began but also because the press has tended to report only those things that support this conclusion. Throughout the trial the media have reported the allegations against the doctors but seem to have neglected to report many of the defence's refutations of the allegations. In the $B M J$, Dyer gave a good account of the strong defence of one of the doctors involved in the case, JamesWisheart, by Elliot Shinebourne, a consultant at a London hospital, and by Martin Elliott, a consultant cardiothoracic surgeon, but this seems to have been ignored by other media. ${ }^{2}$

Not only is the full story not being published, which adversely affects the public, but it seems that the press is also trying to influence the committee hearing the allegations. Without waiting to hear any of the case for the defence, the press has already discussed what will happen if the defendants are acquitted and the inability of the medical profession to regulate itself. This is putting strong external pressure on the committee to return a guilty verdict.

The GMC is in a difficult position and deserves our support. They have had strong pressure from the media, and possibly political pressure as well, to find the defendants guilty. Self regulation must be sustained on the basis of making good decisions, not through the production of a scapegoat. Government regulation of our profession would be preferable to a self regulatory system manipulated by the whim of the media.

Alan Kerr Consultant otolaryngologist Royal Victoria Hospital, Belfast BT12 6BA

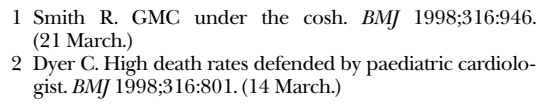

\section{Consent may be hard to obtain for incompetent patients when relatives object}

EDITOR-McFadzean et al introduce an ethical debate that arose when a critically ill patient was unable to give consent to a procedure that she had previously refused to consent to. ${ }^{1}$ The article highlighted a problem that many specialties experience. One important, though less common, issue that was not raised is the unexpected need for urgent surgery or repeat surgery for a life threatening indication in an unconscious patient who has not granted consent and whose representatives object to giving consent or decline to give it.
Several years ago I was involved in the care of a woman who began to bleed heavily after the birth of her second baby by emergency caesarean section, performed under general anaesthesia. She had not regained consciousness by the time a decision had been made to perform a laparotomy to explore the abdomen. Her partner would not consent to this additional procedure even when the life threatening nature of her condition was explained, because it carried a high risk of hysterectomy. When a consultant arrived to explain the dilemma further, consent was still not given. Fortunately, the patient regained consciousness and gave her consent to the procedure, which resulted in a hysterectomy and subsequent full recovery.

This case highlights the fact that case conferences may not always be possible and that rapid decisions may have to be made without considered legal reference. At a training meeting after this case arose, a group of senior consultants decided that, given the fatal implications of not performing surgery rapidly, a laparotomy without consent would have been appropriate had the patient not regained consciousness.

It would have been interesting if the ethical debate had been extended. It could then have included the issue of unexpectedly life threatening situations when the patient's consent neither exists nor is denied but relatives object to a proposed potentially lifesaving procedure or show indecision.

Edward P Morris Research fellow

Hormone Replacement Therapy Research Unit, Department of Obstetrics and Gynaecology, Guy's Hospital, London SE1 9RT

e.morris@umds.ac.uk

1 McFadzean J, Monson JP, Watson JD, Coakley JH; Hoyte P; Caplan AL, Hansen-Flaschen J. Ethical debate: The dilemma of the incapacitated patient who has previously refused consent for surgery. BMJ 1997;315:1530-2. (6 December.)

\section{Foot morbidity and exposure to chiropody}

\section{Purchasers still need to decide about investing in foot health care}

EDIToR-The paper by Harvey et al shows that the organisation of chiropody services in many parts of the country requires greater consideration by purchasers. ${ }^{1}$ Unfortunately, foot health problems remain of low status. Even in 1995, four years after Harvey et al carried out their study, over half (52\%) of those needing chiropody in South Glamorgan had waited over 12 months for treatment after having received an initial assessment by a chiropodist and been assigned to a waiting list. Of these, nearly $12 \%$ had severe foot disease.

South Glamorgan (now Bro Taf) Health Authority responded by extensively reviewing chiropody services and is currently implementing radical changes to the delivery of care. Key features of the service change since 1995 are:
- Referral from primary care only

- Introduction of packages of active care

- Improvement in skill mixing

- Increase in patient and professional education and training

- Reorganisation of clinics to realign the service with primary care and reduce the requirement for domiciliary care by developing transport arrangements for patients

- Abolition of priority groups and opening of the service to all patients on the basis of clinical need

- Introduction of surgical podiatry, supported by orthopaedic surgeons interested in forefoot surgery.

Access has improved (measured by waiting times), and the types of problems referred indicate that foot disease rather than patient demand is starting to drive access. For example, in the first year after the change in the service the proportion of patients receiving chiropody who had diabetes increased from $8.5 \%$ to $10.4 \%$. Important consequences for purchasers are, however, shown by a changing profile of care-during the first 12 months of the new service the manufacture and supply of orthoses increased by $65 \%$.

Our experience highlights the lack of research in and policy guidance on chiropody. A mixed economy has evolved to fill this void, with much of the expressed need being met by the private sector. Whether the NHS could meet this need even with the widespread introduction of the changes proposed by the NHS Executive is debatable. ${ }^{2}$ Adopting a problem focus, with or without the addition of managed access, will increase the pressure on resources. Purchasers who follow the recommendation of Harvey et al to target service provision at those with severe foot morbidity will still have to confront difficult choices about the degree of investment in foot care within the NHS. Unless this is increased, which seems unlikely, rationing will continue. If this becomes explicit and decision making is shared with patients then some progress will have been made.

Quentin D Sandifer Consultant in public healt medicine

Iechyd, Morgannwg Health, Swansea SA1 1LT

Jan Davies Manager

Podiatry Department, Barry Hospital, Barry CF62 8HE

1 Harvey I, Frankel S, Marks R, Shalom D, Morgan M. Foo morbidity and exposure to chiropody: population based study. BMJ 1997;315:1054-5. (25 October)

2 Chiropody Task Force. Feet first. Leeds: NHS Executive, 1994.

\section{Study needs to address several issues}

EDITOR-Harvey et al suggested that chiropody services for the elderly population of South Glamorgan were not led by need. ${ }^{1}$ They used the number of foot problems observed on examination (index 1) as an indicator of foot morbidity and whether the person received chiropody care in the preceding year as the response. They showed, after adjusting for confounders such as sex, age, and living status, that the 
number of foot problems was not significantly associated with receipt of chiropody care in the previous year. Age and sex were, however, significant, suggesting that receipt of chiropodist services was popular among the most elderly women of South Glamorgan, irrespective of whether they had a foot problem. We find this intriguing but have several queries.

We wonder whether the number of foot problems is an appropriate indicator of foot morbidity. Recent work with chiropodists leads us to understand that loss of mobility, pain, infection, tissue breakdown resulting from the foot condition, and existing comorbidity (such as unstable diabetes or neuropathy) are better determinants of need than the number of foot conditions (S Goh, unpublished data).

We wonder whether Harvey et al took into account the interaction between variables, as possible omissions may influence the results of the analysis. Some variables are also related to others-for example, marital status and living alone: if people are married then they do not live alone and, similarly, if people live alone they are probably single, divorced, or separated. Is it therefore necessary to include in the model two or more variables which are possibly measuring the same effect?

The authors did not explain further why the unadjusted odds ratio was reversed in elderly people living alone after they had controlled for confounders such as age and sex. Could this reversal be due to marital status?

The health service needs to know whether current chiropody services are adequately targeted at those in need. This study could be cited with more confidence if the above issues were addressed.

Suan Goh Consultant in public health medicine Lifespan Health Care Cambridge NHS Trust, Cambridge CB1 5EE

Brian Tom Statistician

Centre for Applied Medical Statistics, Department of Community Medicine, University of Cambridge, Cambridge CB2 2SR

1 Harvey I, Frankel S, Marks R, Shalom D, Morgan M. Foot morbidity and exposure to chiropody: population based study. BMJ 1997;315:1054-5. (25 October.)

\section{Authors' reply}

EDITOR-We welcome several of the changes described by Sandifer and Davies, particularly the abolition of demographically defined priority groups, the introduction of surgical podiatry, and the improvement in skill mix (the balance of podiatrists and foot care assistants) required to deliver an effective and efficient service.

Other changes they describe are more problematic. If domiciliary provision is reduced great care must be taken to ensure that arrangements for transport of patients are indeed adequate and that the net effect is not an unintended increase in the overall cost of the service. Neither is it self evident that filtering referrals through primary care will necessarily enhance the extent to which the delivery of care is led by need. The low awareness among most primary healthcare staff of foot problems has been well documented.

We accept Goh and Tom's point that our foot morbidity indices are comparatively crude representations of more complicated phenomena, but simplification is an integral part of exploratory epidemiological studies. We would be delighted if subsequent work were to explore this issue using more complex measures. Marital status and living alone are indeed related to some degree, but the fact that living alone remains significant after adjustment for marital status confirms that they are not simply proxies for each other. Likewise, omitting marital status from the final model does not alter the reversal of the unadjusted relation between receipt of chiropody and living alone, which we can confirm is largely due to adjustment for age and sex. Goh and Tom rightly raise the issue of interactions between variables. None of the first or second order interactions between age, sex, and the foot morbidity indices, however, approach significance. Additionally, the absence of strong significant main effects for the foot morbidity indices would require any interactions to be of an unusual form

In light of this, we agree with Goh and Tom that our findings imply that older women are more likely to see a chiropodist irrespective of the number of foot problems. We believe that this is consistent both with the historical targeting of broadly defined demographic groups and with the social-as much as medical-function of a visit to the chiropodist for many older people. ${ }^{2}$

Ian Harvey Senior lecturer in epidemiology and public health medicine

Stephen Frankel Professor of epidemiology and public health medicine

Department of Social Medicine, Canynge Hall, Bristol BS8 2PR

Ronald Marks Professor of dermatology

David Shalom Dermatology research registrar Department of Dermatology, University of Wales College of Medicine, Cardiff CF4 4XN

Maria Morgan Research officer

Centre for Applied Public Health Medicine, Temple of Peace and Health, Cardiff CF $13 \mathrm{NW}$

1 Kemp J, Winkler JT. Problems afoot:need and efficiency in foot care London: Disabled Living Foundation, 1983. 2 Clarke M. Trouble with feet. London: G Bell, 1969.

\section{General practitioners' self assessment of knowledge}

\section{The vast range of clinical conditions means that doctors cannot know everything}

EDITOR-Factual recall is only one elemen of a needs assessment that should be taken into account in developing continuing medical education programmes for general practitioners. A poor correlation of self assessed knowledge with performance in a knowledge test, as shown by Tracey et al, ${ }^{1}$ does not invalidate the rationale for a needs assessment. The knowledge tests used by Tracey et al do not reflect the range of practical issues relevant to patient management. Knowledge of practical management that is relevant to the concerns and questions likely to be raised by patients, and confidence and experience in dealing with specific conditions, are the needs that should be assessed in planning continuing medical education programmes.

In two studies evaluating guidelines in primary care, one set for the use of magnetic resonance imaging for common orthopaedic conditions (182 general practitioners $)^{2}$ and the other for the management of breast conditions in primary care (113 general practitioners), ${ }^{3}$ we undertook needs assessments with the participating practices. In each study doctors rated their confidence in using magnetic resonance imaging or managing breast conditions respectively and identified problems from recent clinical practice, and knowledge of practically relevant issues was assessed. In the first study the doctors indicated their frequency of using magnetic resonance imaging. Good knowledge of the contraindications for magnetic resonance imaging was associated with higher self assessed knowledge $(\mathrm{P}<0.05)$ and confidence $(\mathrm{P}<0.01)$ and frequency $(\mathrm{P}<0.05)$ of using magnetic resonance imaging in practice. Knowledge of lifetime risk of breast cancer was associated with confidence in dealing with breast conditions $(\mathrm{P}<0.05)$. Knowledge was also associated with membership of the Royal College of General Practitioners $(\mathrm{P}<0.01)$

General practitioners can correctly assess their knowledge and needs if the relevant aspects are explored. Identifying needs from personal experience is perhaps more valid than general rating scales of knowledge; the knowledge that is assessed should be relevant to the discussions that take place with patients and the management issues that arise in combination with up to date factual information. The range of clinical conditions encountered in primary care is too vast for high levels of personal knowledge to be maintained in all these areas. It is more important that general practitioners can access information when required rather than having it readily accessible. The nature of general practice is also characterised by high levels of uncertainty in dealing with many patients' conditions, and general practitioners have to be able to cope with this in everyday practice. ${ }^{4}$ Assessing knowledge of practical management, experience, and confidence can then inform the content and method of an educational programme.

Adrian Edwards Lecture

Michael Robling Matthews Research officer

Sarah Matthews Clinical fellow

Helen Houston Senior lecturer

Clare Wilkinson Senior lecturer

Division of General Practice, University of Wales

College of Medicine, Cardiff CF3 7PN

1 Tracey JM, Arroll B, Richmond DE, Barham PM. The validity of general practitioners' self assessment of 
knowledge: cross sectional study. BMJ 1997;315:1426-8. (29 November.)

2 Robling MR, Kinnersley P, Houston HLA, Hourihan H, Cohen D, Hale J. An exploration of general practitioners use of magnetic resonance imaging: a critical incident study. Fam Pract (in press.)

3 Edwards AGK, Robling MR, Jones J, Pill R, Wilkinson C, BRIDGE Study Team. Women's perception of breast cancer risk. Fam Pract 1996;12:340.

4 Royal College of General Practitioners. The nature of general medical practice. London: RCGP, 1996:27.

\section{Knowledge gaps were identified by general practitioners}

EDITOR-If Tracey et al are correct and clinicians cannot identify their own educational needs then their paper raises important issues about the direction of continuing medical education for general practitioners both in New Zealand and elsewhere. ${ }^{1}$ However, the data they present concerning the correlation between individual general practitioners' self assessment scores and actual scores on testing with a multiple choice questionnaire are open to a more optimistic interpretation.

Reconstructing the data from their original figure (concerning thyroid disorders) into a two by two format (table) suggests that general practitioners can identify gaps in their own knowledge. General practitioners who recorded a self assessment score of 4 or less on the nine point semantic scale indicated that they perceived a gap in their knowledge. If a multiple choice questionnaire score of less than $70 \%$ (the group average was $68 \%$ ) is presumed to confirm a gap in knowledge gap then, while the sensitivity of self assessment is a disappointing $28 \%$, the specificity of self assessment by clinicians is a more encouraging $91 \%$. Although the number of individuals is small, this suggests that when clinicians identify gaps in their own knowledge they are usually right but that their judgment is less reliable when they consider their knowledge to be comprehensive.

General practitioners' self assessment scores and test scores for gaps in their knowledge of thyroid disorders*

\begin{tabular}{lccc}
$\begin{array}{l}\text { Knowledge gap } \\
\text { on self }\end{array} \begin{array}{l}\text { assessment } \\
\text { (score) }\end{array}$ & \multicolumn{2}{c}{$\begin{array}{l}\text { Knowledge gap on multiple } \\
\text { choice question testing }\end{array}$} & \\
\cline { 2 - 3 } & $\begin{array}{c}\text { Yes } \\
\text { (score }<\mathbf{7 0 \% )}\end{array}$ & $\begin{array}{c}\text { No } \\
\text { (score } \geqslant \mathbf{7 0 \% )}\end{array}$ & Total \\
\hline Yes (1-4) & 8 & 2 & 10 \\
\hline No (5-9) & 21 & 19 & 40 \\
\hline Total & 29 & 21 & 50 \\
\hline
\end{tabular}

*Sensitivity 8/29 (28\%); specificity 19/21 (91\%).

One of the multiple choice questions relates to the risk of a patient with toxic nodular goitre developing hypothyroidism after radioiodine treatment. I did not know the correct response and identified a gap in my own knowledge. The authoritative textbook I consulted contained no answer, ${ }^{2}$ while a simple search of Medline identified three recent studies. ${ }^{3-5}$

Rather than attempting to overwhelm clinicians with information in the hope that they will recall it when needed, continuing medical education needs to focus increasingly on helping doctors to identify impor- tant gaps in their knowledge, ideally as they occur in clinical practice. Clinicians should also be provided with the skills to track down and apply the information when they (and their patients) need it. Instead of undermining self directed learning in continuing medical education this research adds support to such an approach.

Mike Crilly Clinical research fellow Department of General Practice, University of Manchester, Manchester M14 5NP

1 Tracey JM, Arroll B, Richmond DE, Barham PM. The validity of general practitioners' self assessment of knowledge: ross sectional study. BMJ 1992:315:1426-8. (29 November: 2 McGregor AM. The thyroid gland and disorders of thyroid function. In: Weatherall DJ, Ledingham JGC, Warrell DA, eds. Oxford textbook of medicine. Vol 2. 3rd ed. Oxford: Oxford Medical, 1996:1613.

3 Berg G, Michanek A, Holmberg E, Nystrom E. Clinica outcome of radioiodine treatment of hyperthyroidism: follow up study. J Intern Med 1996;239:165-71.

4 Franklyn JA, Daykin J, Holder R, Sheppard MC. Radioiodine therapy compared in patients with toxic nodular or Graves' hyperthyroidism. O J Med 1995;88:175-80.

5 Huysmans DA, Hermus AR, Corstens FH, Kloppenbor PW. Long-term results of two schedules of radioiodin PW. Long-term results of two schedules of radioiodine treatment for tox

\section{Testing can be valid only if questions are} relevant to those tested

EDIToR-Tracey et al draw attention to the necessity for professional development programmes for general practitioners to be appropriate to the educational needs of those clinicians. ${ }^{1}$ Unfortunately, their paper makes the assumption that a written true-false test of 50 questions on thyroid disorders is a valid test of general practitioners' educational needs, which can then be compared with their own assessments of that need. This can be the case only if all of the questions in the test are directly relevant to the practice of the general practitioners being tested.

It is fortunate that they give examples of the questions in the true-false test. As a primary care educationalist with an interest in general medicine, I would assess my knowledge and skills in the management of thyroid disorders as being adequate to practise as a general practitioner. I would, however, assess four of the questions as being not relevant to general practice. The question that asks whether an elderly patient with hyperthyroidism may only have symptoms and signs of general debility is valid since ignorance of this fact may result in general practitioners not testing thyroid function in such cases. Knowing whether most patients with toxic nodular goitre become hypothyroid after radioiodine treatment is not relevant, but knowing that some patients may become hypothyroid after radioiodine treatment is relevant and could have been reflected in a valid question.

I therefore dispute the conclusion that "general practitioners' insight into their educational needs is poor." The paper does, however, highlight the need for professional development activities to be based on an objective assessment of needs. More research is needed, but it must not contain invalid assumptions.

Phil Taylor General practice clinical tutor Exeter Postgraduate Medical Centre, Exeter EX2 5DW
1 Tracey JM, Arroll B, Richmond DE, Barham PM. The validity of general practitioners' self assessment of knowledge: cross sectional study. BMJ 1997;315:1426-8. (29 November.)

\section{Author's reply}

Editor-In response to Edwards et al, we were not suggesting that needs assessment was not important; rather we were making a case for it to be done more rigorously. In New Zealand most general practitioners select their continuing education on the basis of their self perceived needs, which was reflected in our initial self assessment questionnaire. What our study showed was that this form of needs assessment is inadequate and a more rigorous assessment such as the one reported by Edwards et al is necessary.

Both Edwards et al and Crilly question how well the knowledge we tested related to practical management in general practice. Our definitive test of knowledge did include case scenarios with choices of management. Also, during the test's development we presented 75 possible true-false questions to a group of eight non-academic general practitioners and asked them to remove all questions they thought were not relevant to their practice. We retained only those questions rated as relevant.

Crilly suggests using a two by two table to analyse the data. Such an analysis of the actual data shows a sensitivity of $24 \%$ and a specificity of $93 \%$ (these are different from Crilly's figures as some of the plots on the figure represented two data points). Where general practitioners had a self assessment score of less than 5 the specificity of the test in predicting that they had a knowledge gap on true-false testing was high; of the 11 who scored themselves this low on the self assessment, nine also scored low on the true-false test. A total of 56, however, scored themselves greater than 5 on the self assessment, and yet $52 \%$ of these had a knowledge gap on testing. A sensitivity of $24 \%$ suggests to us that such a form of self assessment is not useful.

We agree with both Crilly and Taylor that the range of clinical knowledge in general practice is too vast to maintain and that access to information is important. We do, however, have concerns that some general practitioners in our study perceived themselves to have adequate knowledge in areas where their objectively measured knowledge base was poor. They are therefore unlikely to access the available information. We would promote the availability of banks of objective questions that general practitioners could use for self assessment to plan their portfolio of learning each year.

Jocelyn Tracey Assistant director Goodfellow Unit, Department of General Practice, University of Auckland, Private Bag 92019, Auckland, New Zealand 


\section{Preventing RhD haemolytic disease of the newborn}

Revised guidelines advocate two doses of anti-D immunoglobulin for antenatal prophylaxis

EDITOR-In his editorial van Dijk advocates routine antenatal prophylaxis with anti-D immunoglobulin of all pregnant women who are $\mathrm{RhD}$ negative and refers to the consensus conference at the Royal College of Physicians in Edinburgh in April 1997. ${ }^{1}$ He states that two dose schedules were considered-two doses of 500 IU of anti-D immunoglobulin, one at 28 weeks' gestation and the other at 34 weeks, and one dose of 1000 IU given between 28 and 30 weeks-both options being equally effective. He implies that the second option reflects Bowman's practice in Canada. ${ }^{2}$ Bowman's programme in fact uses a dose of $1500 \mathrm{IU}$ given at 28 weeks; maternal anti-D immunoglobulin concentrations are then monitored and additional anti-D immunoglobulin is given at around 36 weeks to those women in whom passive anti-D immunoglobulin is no longer detectable.

In my presentation to the conference the second option considered was a single dose of $1500 \quad$ IU-not 1000 IU-of anti-D immunoglobulin at 30 weeks. In the final consensus statement the panel did not indicate a preference between these options and was satisfied that "both seem to work." A dose of $1000 \mathrm{IU}$ of anti-D immunoglobulin was never considered as the rate of its decay would mean that little or none would remain in a woman's circulation towards the end of pregnancy, when fetomaternal haemorrhage is known to occur more frequently.

Revised guidelines on the use of anti-D immunoglobulin from the British Blood Transfusion Society and the Royal College of Obstetricians and Gynaecologists agree that the preferred option is two doses of 500 IU of anti-D immunoglobulin. ${ }^{3}$ This option was chosen partly because it uses less anti-D immunoglobulin-a scarce resource-than a single dose of $1500 \mathrm{IU}$ and partly because two doses of $500 \mathrm{IU}$ given at 28 and 34 weeks achieve a higher circulating concentration of anti-D immunoglobulin as term approaches than does the single larger dose. The revised guidelines were also prompted by the absence of published data on the clinical outcome of giving a single dose of $1500 \mathrm{IU}$ at 30 weeks.

Douglas Lee Consultant in transfusion medicine National Blood Service Lancaster, PO Box 111, Lancaster LA1 4GT

1 Van Dijk B. Preventing RhD haemolytic disease of the newborn. BMJ 1997;315:1480-1. (6 December.)

2 Bowman JM. The prevention of Rh immunisation. Transfu sion Med Rev 1988;2:129-50.

3 Lee D, Contreras M, Robson SC, Rodeck CH, Whittle MJ. Guidelines for the use of anti-D immunoglobulin for $\mathrm{Rh}$ prophylaxis. Br J Obstet Gynaecol 1998;105:129-34.

Services should be centralised for pregnancies affected by RhD haemolytic disease

EDITOR-In their article on the underreporting of mortality from RhD haemolytic disease in Scotland, Whitfield et al highlight an important issue. ${ }^{1}$ We recently completed a study on the outcome of all pregnancies affected by $\mathrm{RhD}$ antibody in Northern Ireland from October 1994 to February 1997 (presented at the autumn 1997 meeting of the Irish Perinatal Society, Portiuncula Hospital, Country Galway, Republic of Ireland). Of the 124 pregnancies affected by $\mathrm{RhD}$ antibody, five were spontaneous abortions, one a stillbirth of unknown cause (no signs of hydrops), and two stillbirths after intrauterine blood transfusions-one at 25 weeks' gestation and the other at 27 weeks. Only one neonatal death (1.6 per 10000 live births) was reported.

Mortality should not, however, be the only concern with $\mathrm{RhD}$ haemolytic disease. Of the 78 babies affected by $\mathrm{RhD}$ isoimmunisation in our study, five had minor developmental problems and two had major permanent neurodevelopmental problems at 2 years of age. Thirty two of the 124 babies were born in hospitals that could not offer paediatrician led neonatal care, and nine of these babies had to be transferred to another hospital for their care.

We support the introduction of routine antenatal prophylaxis with anti-D immunoglobulin as this has repeatedly been shown to reduce the rate of maternal alloimmunisation. Given the morbidity and mortality associated with $\mathrm{RhD}$ haemolytic disease, a reduction in the disease's incidence should lead to both short and long term health gains for vulnerable babies.

To accompany the introduction of an antenatal prophylaxis programme with anti-D immunoglobulin we advocate the centralisation of services for affected pregnancies; with fewer affected mothers and babies, the training and maintenance of skills for obstetricians and neonatologists can only be guaranteed in this way.

J S Craig Research fellow

B G McClure Professor of neonatal medicine Department of Child Health, Queen's University of Belfast, Institute of Clinical Science, Belfast BT12 6BJ

T R J Tubman Consultant neonatologist Belfast City Hospital, Belfast BT9 7AB

1 Whitfield CR, Rafat A, Urbaniak SJ Underreporting of mortality from $\mathrm{RhD}$ haemolytic disease in Scotland and its implications: retrospective review. BMJ 1997;315:1504-5. (6 December.)

\section{Mortality and distribution of income}

\section{Societies with narrower income distributions are healthier}

EDITOR-Gravelle's recent contribution to the debate on the relation between income distribution and health may have been difficult reading for some. ${ }^{1}$ I offer a simple analogy by way of explanation.

Imagine two identical fields, both of which are manured with equal quantities of a fertiliser. In one field the fertiliser is spread evenly; in the other some plots receive far more fertiliser than others. At harvest, the yield is considerably higher in the evenly treated field. One possible explanation of this result is that, in the unevenly treated field, plants growing faster and higher in plots receiving more fertiliser have drawn moisture away from those less well treated and have also shaded them from the sun. This is analogous to the relative income hypothesis.

An alternative explanation is simply that the first $\mathrm{kg}$ of fertiliser spread on a given plot produces a greater increase in yield than does the second. The optimal application of fertiliser is therefore to spread it as evenly as possible. This is analogous to the absolute income hypothesis. This second explanation works at the level of individual plants and does not need to consider interactions between plants. In the same way, the absolute income hypothesis for health considers only the direct effect of income on the health of an individual. On the other hand, the relative income hypothesis requires that the incomes of others affect the health of an individual through complex societal mechanisms.

Gravelle's examination is important. The absolute income hypothesis is a simpler explanation than the relative income hypothesis for the observation that, other things being equal, societies with narrower income distributions are healthier. The more complex hypothesis should not be asserted until the claims of the simpler one have been exhausted. In saying, however, that "studies using population level data ... cannot distinguish between the absolute income and relative income hypotheses," he goes too far. Some reasonable modelling may be attempted using aggregate data, provided enough is known about income distribution. For example, if the richest people in society A are poorer than the poorest in society B but $\mathrm{B}$ has a much greater income inequality and also worse health, this will cast doubt on the absolute income hypothesis.

Stephen Senn Professor of pharmaceutical and health statistics

Department of Epidemiology and Public Health, Department of Statistical Science, University College London, London WC1E 6BT

1 Gravelle H. How much of the relation between population mortality and unequal distribution of income is a statistical artefact? BMJ 1998;316:382-5. (31 January.)

\section{Low relative income affects mortality}

EDITOR-Gravelle's explanation of why more egalitarian societies tend to have lower mortality rates is neither new nor true. ${ }^{1}$ The fact that an additional income of $£ 1$ per person made more difference to the health of the poor than that of the rich was initially my stated reason for looking at income distribution. Twelve years $\mathrm{ago}^{2}$ and twice since I showed data on the curvature of the relation between individual income and health. Gravelle does not provide data and ignores the published reasons for abandoning this explanation of the income distribution relation.

His view requires a strong, and strongly curvilinear, relationship between absolute (not relative) income and mortality among rich developed countries. The evidence contradicts all of these. The relation between 
gross national product per head and life expectancy puts the rich Organisation for Economic Cooperation and Development (OECD) countries all on the near linear, near horizontal part of the international curve. $^{3}$ Even at half the average income of the United States (the threshold defining relative poverty) the relation is still weak and almost linear. Likewise, the correlation between median income and mortality among the 50 states of the United States is only -0.26 . Rather than a stronger relation with median income being, as Gravelle suggests, confounded by income distribution, controlling for income distribution reduces this correlation to a non-existent -0.06 .

The same is true across developed countries. Contrary to what Gravelle's model predicts, health inequalities have not been reduced during the past half century of economic growth, even when growth has "trickled down." Nevertheless, the only study using matched data shows that health inequalities are closely related to income inequalities internationally. ${ }^{4}$

Although there is no strong curvilinear relation with absolute levels of income between countries, poor people in the United States often have death rates comparable with people in Bangladesh. Their high death rates are not so much a product of their absolute living standards (with freezers, central heating, CDs, and sometimes air conditioning) but reflect their low relative incomes and social status untouched by economic growth. Since mortality is associated with relative income the inequality relation is not an ecological fallacy.

Gravelle misrepresents my argument. ${ }^{3}$ Rather than asserting that someone with a given income will be healthier in a more egalitarian society, I suggest that the main effect is through individual relative income. Someone with an absolute income that equals half the United States average income might do better to be moderately well off in Greece or Spain than poor in the United States. Mortality is lower in more egalitarian societies because the burden of relative deprivation is smaller. This ties in with the evidence that psychosocial effects of low social status that damage health and that have been show in experiments among non-human primates, are also found among human beings. ${ }^{5}$ That the psychosocial effects are widespread is shown by the growing evidence that more egalitarian societies are more cohesive. ${ }^{3}$

Richard G Wilkinson Professorial research fellow Trafford Centre for Graduate Medical Education and Research, University of Sussex, Brighton BN1 9RY

1 Gravelle H. How much of the relation between population mortality and unequal distribution of income is a statistical artefact? BMJ 1998;316:382-5. (31 January.)

2 Wilkinson RG. Income and mortality. In: Wilkinson RG, ed. Class and health:research and longitudinal data. London: Tavistock, 1986. (Chapter 6.)

3 Wilkinson RG. Unhealthy Societies: the afflictions of inequality. London: Routledge, 1996.

4 van Dooslaer E, Wagstaff A, Bleichrodt H, Calonge S, Gerdtham U, Gerfin M, et al. Income-related inequalities in health: some international comparisons.J Health Econ 1997;16:93-112.

5 Brunner E. Stress and the biology of inequality. BMJ 1997;314:1472-6.

\section{Widening income inequalities cause} poorer health

EdiTor-If the rich get richer their health will improve only slightly, whereas if the poor get poorer their health will suffer greatly. Widening income inequalities will therefore worsen overall health. This is, however, far from being an artefact as Gravelle suggests ${ }^{1}$; rather, it actually reveals the causal mechanisms.

Consider the privatisation of the water industry. Many wealthy people profited from share dealings, either directly or indirectly through holdings such as personal equity plans. A few water company directors became wealthy-some even fabulously wealthy. At the other end of the scale, however, thousands of people were made redundant and impoverished. Widening inequality does not just mean the flattening of a symmetrical bell shaped curve, but the aggrandisement of the few at the expense of the many.

When this is translated into health behaviours, the equations of price, income, and consumption for the bulk of the population break down at the extremes. Those enriched might buy more expensive wines and entertain more lavishly, but their personal intake of alcohol is unlikely to increase. Those cast into poverty may actually drink more and in a more uncontrolled and self damaging fashion. In other words, alcohol may be an example of negative elasticity or Giffens paradox, as potatoes in the Irish famine were said to be.

The health impact may be amplified by a multiplier effect. The wealthy directors of the water companies found their new situation delightful and pursued policies to entrench it. They sought to disconnect late payers or make them pay more through metering. They became obsessed with financial deals and lost sight of their core business-water supply-so that parts of the country teetered on the edge of drought. They blocked fluoridation and thereby disadvantaged the poorest people, who have the worst dental health.

Similar examples can be drawn from transport, housing, mining, and energy. An underpinning theme is the loss of the "hidden wage" or "social income," so that the poorest people are impoverished even if their money wage is unchanged.

I therefore believe that widening inequalities cause poorer health, although I accept Gravelle's caution about the strength of the effect. Indeed, there have been times in the past decade when I have wondered if poorer health was not the object of the exercise.

Graham C Sutton Senior clinical lecturer Nuffield Institute for Health, Leeds LS2 9PL

1 Gravelle P. How much of the relation between population mortality and unequal distribution of income is a statistical artefact? BMJ 1998;316:382-5. (31 January.)

\section{Author's reply}

EDITOR-My purpose was not to propose a new theory but to draw attention to a problem in the interpretation of population level studies that are used to support the argument that the health of a person is influenced by his or her relative income. Senn's analogy is a helpful illustration of the artefactual problem.

Wilkinson makes a number of points in saying that the argument is incorrect.

Firstly, he states that it requires a non-linear aggregate relation between population health and mean income, and then he says that across developed countries the relation is linear. The argument requires, however, that the relation between health and income in individual people is nonlinear.

Secondly, he says that the international association between inequalities in health and in income ${ }^{1}$ supports the relative income hypothesis. In fact, this association is irrelevant for distinguishing between the relative and absolute income hypotheses. It would arise if health were positively related to income, in a linear or non-linear way. Hence both the relative income and the non-linear absolute income hypothesis would predict the reported association.

Thirdly, Wilkinson says that I misinterpreted his version of the relative income hypothesis. Since he still posits, however, that more equal societies will have better health, the artefactual argument still applies. Both the relative income hypothesis and the non-linear absolute income hypothesis yield the same prediction about the correlation of health and income inequality in populations.

Recent evidence suggests that the aggregate level correlations between population health and income inequality may be very weak. ${ }^{2}$ A study that used data on individual people showed that aggregation can lead to misleading conclusions. ${ }^{3}$ It found that aggregating the individual data to area level produced negative correlations between population health and income inequality but that area income inequality had no effect on individual health once individual income was allowed for.

Relative income or social position could well have an effect on the health of individual people, as Wilkinson and Sutton suggest. We require more studies that combine individual cohorts and careful specification of the hypothesised relation to take account of the influences of lifestyle, consumption, environment, and income on health, as well as of the effect of health on income. $^{4}$

Hugh Gravelle Professor of economics

National Primary Care Research and Development Centre, Centre for Health Economics, University of York, York YO1 5DD

1 Van Doorslaer E, Wagstaff A, Bleichrodt H, Calonge S, Terdtham U, Gerfin M, et al Income related inequalities in Gealth: some international comparisons. J Health

2 Judge K, Mulligan J, Benzeval M. Income inequality and population health, Soc Sci Med 1998;46:567-79.

3 Fiscella K, Franks P. Poverty or income inequality as predictor of mortality: longitudinal cohort study. BMJ 1997;314:1724-7.

4 Ettner SL. New evidence on the relationship between income and health. J Health Econ 1996:15:67-86. 